\title{
Time-Derivative Filter for Detection of Moving Objects by Adaptive Identification Method
}

\author{
Soon-Hyn Park Non-member (Oita University, park@cc.oita-u.ac.jp) \\ Takami Matsuo Member (Oita University, matsuo@cc.oita-u.ac.jp)
}

Keywords: Time-derivative tracker, motion detection, background estimation, adaptive observer

To detect the moving objects in an image sequence is a very important low-level task for many computer vision applications, such as video surveillance, traffic monitoring, and sign language recognition. A large set of motion detection algorithms has already been proposed in the literature. They are filed into four categories according to the type of inter-frame computations. The first one is based on temporal gradient: a motion likelihood index is measured by the instantaneous change in the image intensity computed by differentiation of consecutive frames. The second category is the background subtraction techniques. In the absence of any a priori knowledge about target and environment, the most widely adopted approach for moving object detection with fixed camera is based on background subtraction. The principle of these methods is to build a model of static scene (i.e. without moving objects) called background, and then to compare every frame of the sequence to this background in order to discriminate the regions of unusual motion, called foreground (the moving objects). Many algorithms have been developed for background subtraction. The most important steps in a background subtraction algorithm are background modeling and foreground detection. In particular, background modeling is at the heart of any background subtraction algorithm. Much research has been devoted to developing a background model that is an estimate of background. The background model is computed by the difference between the current frame and the current background model. The background model should be robust against environmental changes in the background, but sensitive enough to identify all moving objects of interest. A significant number of the described algorithms use a simple IIR filter applied to each pixel inde- pendently to update the background and use thresholding to classify pixels into foreground/background. The third type of approach is based on the computation of the local apparent velocity (optical flow) that is used as input of a spatial segmentation. This method is in general more computationally complex and it is sensitive to the reliability of the optical flow. The fourth method is based on morphological filters. By using spatio-temporal structuring elements, a local amplitude of variation can be computed as motion likelihood index. Such measure can be useful to detect small amplitude motion, but it is sensitive to outliers. In particular, Richefeu et al. presented a new differential operator based on a hybrid filter, combining morphological and linear operations. It computes a pixel-wise amplitude of time-variation over a recursively defined "temporal window". It is particularly suited to small and low amplitude motion.

This paper presents a new differential filter of a nonlinear function of intensity (nonlinear intensity) for each pixel to detect moving objects within a scene acquired by a stationary camera. The estimated variety of the nonlinear intensity is obtained by using the adaptive identification theory. We select two nonlinear functions, a quadratic function and logarithmic function, in order to attenuate the variety of disturbances with small amplitudes, because the filter should have certain noise immunity such as waving bushes or flowing water. As our differential filter recursively updates the estimate of variety of nonlinear intensity, its computational cost is very low. The MATLAB simulation is performed to demonstrate its performance. The proposed method allows us to attenuate the influence of the noise in the high intensity data. 


\title{
論 文
}

\section{適応同定法による時間微分フィルタと移動体検出への応用}

\author{
非会員 朴 淳鉝* 正 員 松尾 孝美**
Time-Derivative Filter for Detection of Moving Objects by Adaptive Identification Method \\ Soon-Hyun Park*, Non-member, Takami Matsuo**, Member
}

\begin{abstract}
This paper presents an adaptive scheme to estimate the time-derivative of a signal without any knowledge of its dynamics. The adaptive estimator is formulated as an adaptive observer with the $\sigma$-modification update law. The algorithm is applied to an adaptive differential filter for the detection of moving objects within a scene acquired by a stationary camera. We adopt four nonlinear intensity functions to reduce the influence of measurement noises. The MATLAB simulations are performed to demonstrate its performance.
\end{abstract}

キーワード : 時間微分器。運動検出, 背景画像推定, 適応オブザーバ

Keywords : Time-derivative tracker, motion detection, background estimation, adaptive observer

\section{1. まえがき}

マルチメディア技術の発達により, 動画データの利用も 盛んになってくるとともに, 自動監視システムのように, そのデータの内容を自動的に理解する手法が注目を集めて いる。これまで種々の運動検出アルゴリズムが提案されて いる。これらは,フレーム間計算のやり方から 4 つのカテゴ リに分けることができる(1) (3)。第一の方法は時間勾配に基 づくものである。第二の方法は背景差分法によるものであ り, 対象や環境に関する予備情報がない固定カメラによる 移動体検出では最もよく使われている。第三の方法は局所 的なみかけの速度であるオプティカルフロー計算に基づく ものである。第四の方法はモルフォロジーフィルタを用い るものである。これらの手法の中で最も処理が早いのは, フレーム間微分を行う時間勾配に基づくものである。しか しながら,勾配計算はノイズを増幅したり，照明の変化や背 景画像のゆらぎなどの影響を受けやすいという久点があ る。このことから擾乱の影響を受けにくい微分器を構成す る必要がある。最近, Ibrir は高階微分までを状態変数とし て状態推定を行うオブザーバを構成し，これを線形時間微 分トラッカーと呼んでいる(4)。この時間微分トラッカーは出 力信号の高階までの時間微分值を求めるものであり, 出力

\footnotetext{
* 大分大学大学院工学研究科

厂 870-1192 大分市旦野原 700

Graduate School of Engineering, Oita University,

700 Dannoharu, Oita, 870-1192

** 大分大学工学部福祉環境工学科

T870-1192 大分市旦野原 700

Department of Human Welfare Engineering, Oita

University, 700 Dannoharu, Oita, 870-1192
}

信号から構成される非線形関数の時間微分を求めるもので はない。

本論文では, 適応パラメータ更新則を用いて, 出力信号 である輝度データから構成される非線形関数の時間微分值 を推定する適応オブザーバを提案する。ついで, 提案した 推定器を動画像内の指定したピクセルにおける移動体の通 過検出に適用する。ここでは, 輝度データの非線形関数の 時間微分值をピクセルごとに推定することにより, 当該ピ クセルを移動体が通過したかどうかを判定する方法を採用 している。最後に, MATLABによるシミュレーションによ り, フレーム間差分および $\mathrm{M}$ 推定を用いた背景画像処理法 と比較し，ノイズに対する耐性を検証する。

\section{2. 非線形輝度関数の時間微分の適応推定}

〈2·1〉適応オブザーバ設計 時刻 $t$ におけるある指 定したピクセルの輝度を $x(t)$ とおく。輝度の特徴を抽出す る非線形関数を $f(x(t))$ (以後, 非線形輝度関数とよぶこと にする）とし, その導関数を $l(t)$ とおく。このとき, 次式が 成立する。

$$
l(t)=\frac{d f(x(t))}{d t}=\frac{d f(x)}{d x} \frac{d x}{d t}
$$

逆関数 $\xi(t)=\left(\frac{d f(x)}{d x}\right)^{-1}$ が存在するとき, 上式はつぎのように 書き換えられる。

$$
\frac{d x(t)}{d t}=\xi(t) l(t)
$$

上式から微分器を用いずに, 入手可能な信号 $x(t), \xi(t)$ を用い 
て $l(t)$ を推定する問題を考える。そこで, 適応パラメータ更 新則を用いるために, $l(t)$ は, 次式のように時変数の多項式 として表せると仮定する。

$$
l(t)=\sum_{k=0}^{N} l_{k} t^{k}
$$

ただし， $l_{0}, \cdots, l_{N}$ は定数とする。（2)式はつぎのように定数 パラメータを用いて変形することができる。

$$
\frac{d x(t)}{d t}=\theta^{T} \varsigma(t)
$$

ただし，つぎのようにおいている。

$$
\theta=\left[\begin{array}{c}
l_{0} \\
l_{1} \\
\vdots \\
l_{N}
\end{array}\right], \varsigma(t)=\left[\begin{array}{c}
\xi(t) \\
t \xi(t) \\
\vdots \\
t^{N} \xi(t)
\end{array}\right]
$$

(4)式において, 入手可能なベクトル信号 $x(t), \varsigma(t)$ から定数 ベクトルを推定する適応オブザーバを次式で定義する。

$$
\frac{d \hat{x}(t)}{d t}=\hat{\theta}(t) \varsigma(t)-q(\hat{x}(t)-x(t))
$$

ただし， $q$ は任意の正数で, $\hat{\theta}(t)$ は定数ベクトル $\theta$ の推定 值で, 次式で与えられる。

$$
\hat{\theta}(t)=\left[\begin{array}{c}
\hat{l}_{0}(t) \\
\hat{l}_{1}(t) \\
\vdots \\
\hat{l}_{N}(t)
\end{array}\right]
$$

このとき, 非線形輝度関数 $f(x(t))$ の微分 $l(t)$ の推定值は次 式で与えられる。

$$
\hat{l}(t)=\sum_{k=0}^{N} \hat{l}_{k}(t) t^{k}
$$

ここで, $\hat{l}(t)$ の更新式を求めるために, 次式のように $2 つ の$ 誤差を定義する。

$$
\left.\begin{array}{l}
e(t)=\hat{x}(t)-x(t) \\
\tilde{\theta}(t)=\hat{\theta}(t)-\theta
\end{array}\right\}
$$

(4),（6)式より，つぎの誤差方程式が得られる。

$$
\frac{d e(t)}{d t}=-q e(t)+\tilde{\theta}^{T}(t) \varsigma(t)
$$

このとき, 次式の標準的な勾配型適応パラメータ更新則を 用いると， $e(t)$ の漸近安定性を保証することができる(5)(6)。

$$
\dot{\hat{\theta}}(t)=\dot{\tilde{\theta}}(t)=-\gamma_{1} \varsigma(t) e(t)
$$

ただし， $\gamma_{1}$ は任意の正数とする。さらに， $\varsigma(t)$ に関して， ある正数 $c, T$ に対して, persitently exciting 条件

$$
\int_{t}^{t+T} \varsigma(\tau) \varsigma(\tau)^{T} d \tau \geq c I, \forall t \geq 0
$$

が成り立つとき， $\tilde{\theta}(t)$ の漸近安定性も保証することができ る。(11)式を用いることにより, 輝度の微分值の推定 $\hat{\dot{x}}(t)$ と 非線形輝度関数の微分值の推定 $\hat{l}(t)$ を次式のように得るこ とができる。

$$
\left.\begin{array}{r}
\hat{\dot{x}}(t)=\hat{\theta}^{T}(t) \varsigma(t) \\
\hat{l}(t)=\sum_{k=0}^{N} \hat{l}_{k}(t) t^{k}
\end{array}\right\}
$$

〈2·2〉非線形輝度関数の選択 移動体検出に適用す る場合には，つぎのように， 2 次関数，対数関数，逆数，お よびロジスティック関数の 4 つの非線形関数を用いるもの とする。ここで, これらの関数は正規化された輝度 $0 \leq x(t) \leq 1$ に対して単調増加し, かつ下に凸であり, 注輝度 データの時間変動における重要性を減じるような関数を 4 つ選んでいる。

$$
\left.\begin{array}{l}
f_{1}(x)=\frac{1}{2} x^{2}(t) \\
f_{2}(t)=\log x(t) \\
f_{3}(t)=-\frac{1}{x(t)} \\
f_{4}(t)=\log (\cosh (x(t)))
\end{array}\right\}
$$

このとき, 輝度に関する導関数は次式で与えられる。

$$
\left.\begin{array}{l}
\frac{d f_{1}(x)}{d x}=x(t) \\
\frac{d f_{2}(t)}{d x}=\frac{1}{x(t)} \\
\frac{d f_{3}(t)}{d x}=\frac{1}{x^{2}(t)} \\
\frac{d f_{4}(t)}{d x}=\tanh (x(t))
\end{array}\right\}
$$

このとき, 輝度に関する導関数の逆 $\xi(t)$ はつぎのように選 ばれる。

$$
\left.\begin{array}{l}
\xi_{1}(t)=\frac{1}{x(t)} \\
\xi_{2}(t)=x(t) \\
\xi_{3}(t)=x^{2}(t) \\
\xi_{4}(t)=\frac{1}{\tanh (x(t))}
\end{array}\right\}
$$

ここで, $\xi_{1}(t), \xi_{4}(t)$ についは, ゼロ割を回避するために, つぎのような不感帯を設ける。

$$
\xi_{i}(t)=\left\{\begin{array}{cc}
\left(\frac{d f_{i}(x)}{d x}\right)^{-1} & ,(x>\varepsilon) \\
\frac{1}{\varepsilon} & ,(0 \leq x<\varepsilon)
\end{array}\right.
$$

〈2·3〉 ディジタル化＼cjkstart輝度データはフレームごとの 離散時間信号であるので, 前述の連続時間アルゴリズムで の微分をつぎのように差分近似する。

$$
\left.\begin{array}{l}
\dot{\hat{x}}\left(t_{k}\right)=\frac{\hat{x}[k+1]-\hat{x}[k]}{h} \\
\dot{\hat{\theta}}\left(t_{k}\right)=\frac{\hat{\theta}[k+1]-\hat{\theta}[k]}{h}
\end{array}\right\}
$$

ただし,$k$ はフレーム番号で, $h$ はビデオレートで, $t_{k}$ は フレーム番号 $k$ の時刻である。これから, 適応オブザーバ による微分推定器は次式のようになる。 


$$
\left.\begin{array}{rl}
\hat{x}[k+1] & =\hat{x}[k]+h\left\{\hat{\theta}^{T}[k] \varsigma[k]-q e[k]\right\} \\
\hat{\theta}[k+1] & =\hat{\theta}[k]-\gamma_{2} \varsigma[k] e[k] \\
e[k] & =\hat{x}[k]-x[k]
\end{array}\right\}
$$

ただし， $\gamma_{2}$ は任意の正数である。さらに，ノイズに対処す るために，上式のパラメータ更新則を $\sigma$ 修正則(5)(6)を用い て, 次式のように変更する。

$$
\hat{\theta}[k+1]=(1-\sigma) \hat{\theta}[k]-\gamma_{2} \varsigma[k] e[k]
$$

ただし， $0 \leq \sigma \leq 1$ とする。このとき，フレーム番号 $k$ におけ る輝度の微分值の推定 $\hat{\dot{x}}[k]$ と非線形輝度関数の微分值の推 定 $\hat{l}[k]$ を次式のように得ることができる。

$$
\left.\begin{array}{l}
\hat{\dot{x}}[k]=\hat{\theta}^{T}[k] \varsigma[k] \\
\hat{l}[k]=\sum_{j=0}^{N} \hat{l}_{j}[k] t_{k}^{j}
\end{array}\right\}
$$

\section{3. シミュレーション}

本章では, 提案した適応オブザーバによる微分推定器を 動画像における移動体検出に応用し，フレーム差分および M 推定法を用いた背景画像推定を利用した移動体検出と比 較する。シミュレーションにはMATLABを用いる。

〈3.1〉 正弦波信号の微分推定 用いるデータは図 1 に示す次式のノイズの付加された正弦波信号系列である。

$$
x[k]=1+\sin t_{k}+0.01 w\left(t_{k}\right) ; t_{k}=k / 30, k=1, \cdots, 500
$$

ただし, $w\left(t_{k}\right)$ は平均 0 , 分散 1 の正規性白色雑音とする。 図 2 の実線が，差分近似による微分推定值を表しており， ノイズの影響を受けていることがわかる。ここで，差分近 似の初期值は第 1 フレームの值を用いている。図 3 の実線 が我々の提案している適応微分推定器で, $f(x)=x$ とした場 合の推定結果である。ただし，シミュレーションで用いた 微分推定器では, (3)式における多項式近似は用いずに, $N=0$ として推定を行っているが, 十分な推定性能が得られ ている。また, 設計パラメータと初期值は, つぎのように 選んでいる。

$$
q=0.195, \gamma_{2}=0.3, \sigma=0.1, \hat{\theta}(0)=0
$$

図 3 の適応微分器による微分推定值には、若干の時間遅れ

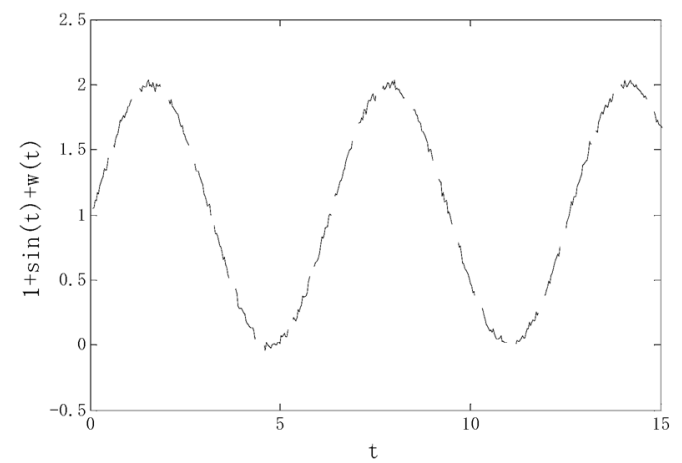

図 1 ノイズの付加された信号系列

Fig. 1. The data sequnece with additive noises.

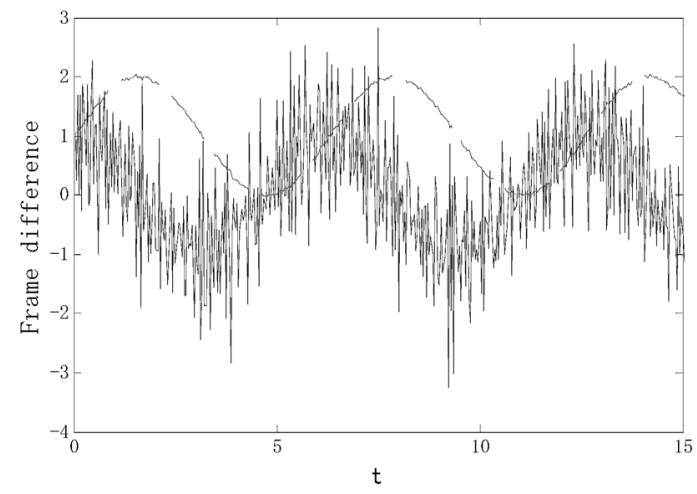

図 2 データ系列（破線）とフレーム差分（実線）

Fig. 2. The data sequence(dotted line) and the frame difference (solid line).

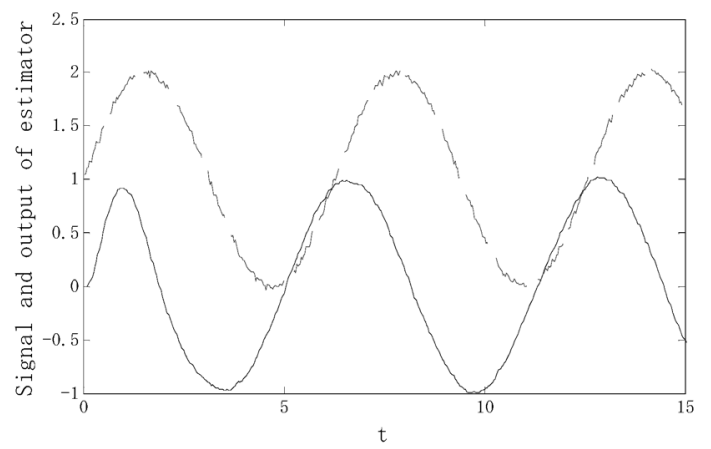

図 3 データ系列（破線）と適応微分器出力（実線）

Fig. 3. The data sequence (dotted line) and the output of the adaptive estimator (solid line).

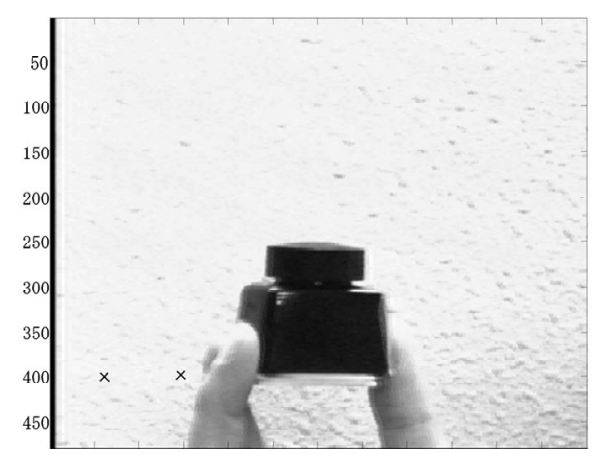

（a）ノイズのない場合

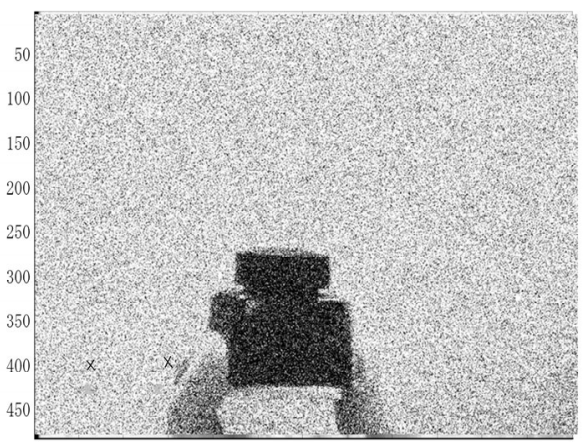

（b）ノイズのある場合

図 4 第 1 フレームの画像データ

Fig. 4. The image of frame \#1. 
を伴っている。この遅れは， $\gamma_{2}$ を大きくすることによって 小さくできるが，ノイズの影響を受けやすくなる。なめら かさを優先したためにこのような值をとっている。

〈3-2〉移動体の通過検出用いるデータは白い壁面 を背景で黒いインク壼を左右に往復して振るシーンを固定 されたカメラで撮影した画像で $640 \times 480$ ピクセル, 101 フ レーム, 8-bit RLE 圧縮の avi 動画データであり, 図 4(a) はその中の第 1 フレームである。伝播ノイズや送受信機の 熱雑音等によるノイズに対する耐性を検証するために，こ の動画データを MATLAB に取り込み, 画像全体に白色ガウ スノイズを付加した動画データを生成する。その動画デー タの第 1 フレームを図 4(b)に示す。ただし, フレームごと に imnoise(*,'gaussian',0,0.1)を用いて, uint8（符号なし8 ビット）データを $[0,1] の$ 範囲の倍精度実数型に変換された データに平均 0 , 分散 0.1 の白色ガウスノイズを付加させて いる。提案手法は指定したピクセルごとの時系列処理であ るので, 簡単に有効性を検証するために, 2 つのピクセル $(150,400)$ と $(70,400)$ を対象とし, 各々ノイズのない場合と ノイズのある場合（前述の方法で平均 0 , 分散 0.1 の白色力゙ ウスノイズを付加したもの）について，提案手法を適用す る。ここで, ピクセル座標は（横軸, 縦軸) ととっている。

まず，ピクセル $(150,400)$ 上の輝度時系列において，ノイ ズのない場合と前述の平均 0 , 分散 0.1 の白色ガウスノイズ が付加されたものを観測データとして, 高輝度の壁面の上 を低輝度のインク壼と高輝度低コントラストの指が通った かどうかを判定して本論文で提案したアルゴリズムの有効 性を示す。図 5(a)にピクセル（150，400）でのノイズのな い輝度を $[0,1]$ で正規化した時系列データを示す。また, 図 5(b) に平均 0 , 分散 0.1 の白色ガウスノイズが付加された 正規化輝度時系列データを示す。提案したアルゴリズムの 設計パラメータはつぎのように選ぶ。

$$
\gamma_{2}=0.25, \sigma=-0.8, q=0.01
$$

図 6(a)は図 5(a)を, 図 6(b)は図 5(b)を観測データとしたフ レーム差分值であり, この值が大きい時に移動体が指定し たピクセルを通過したと判定することができる。しかし，

ノイズの影響により指定されたピクセル上を移動体が通過 しているかどうかの判定は難しいことがわかる。一般的に 最もよく使われているフレーム差分による微分推定器はノ イズの影響を受けやすい欠点があることが図 6 からわかる。 島井らの M 推定法(7)による背景画像推定法を適用したもの が図 7(a),(b)である。M 推定による背景画像推定の場合もノ イズがない場合には背景画像をうまく推定できるがノイズ のある図 7(b)の場合は移動体と背景の区別ができてないこ とがわかる。図 8 から図 11 は提案した適応推定器を用いた 結果である。ここで, 各々非線形輝度関数を $f_{1}(x), f_{2}(x), f_{3}(x), f_{4}(x)$ としている。ただし, 提案した微分推 定器では前節と同様に( 3 )式における多項式近似は用いず に，N=0 として推定を行っているが，十分な推定性能が得 られている。図 8(a),(b)は 2 次関数 $f_{1}(x)$ による微分值の推 定を示している。ノイズがある場合でも，インク㤠が指定
したピクセルを通った所を検出できていることがわかる。 図 9(a),(b) は輝度の非線形関数として選択した対数関数 $f_{2}(x)$ によって微分值を推定したものである。図 10(a),(b) は輝度の非線形関数として輝度の逆数 $f_{3}(x)$ によって微分 值を推定したものである。図 11(a),(b)は輝度の非線形関数 としてロジスティック関数 $f_{4}(x)$ によって微分值を推定し たものである。ノイズのない場合, 急激な輝度変化の検出 は， $f_{2}(x), f_{3}(x), f_{4}(x)$ を用いた場合のすべてで難しいことが わかる。ノイズのある場合, $f_{2}(x), f_{3}(x), f_{4}(x)$ を用いたすべ ての場合で, 低輝度でのノイズの影響の抑制効果が大きい が，高輝度でのノイズの影響を抑制できていないことがわ かる。これは, 選択した非線形輝度関数では比較的, 輝度 の高いところでは，あまりノイズを減じることができない ことを意味している。つぎに, 図 $12(\mathrm{a})$ にピクセル $(70,400)$ でのノイズのない輝度を $[0,1] て ゙$ 正規化した時系列データを 示す。また, 図 $12(\mathrm{~b})$ に平均 0 , 分散 0.1 の白色ガウスノイ ズが付加された正規化輝度時系列データを示す。図 13,14 に,ノイズがある場合において, フレーム差分による微分 推定およびM推定による背景画像推定の結果を示す。また, 図 15,16 に,ノイズがある場合において, 非線形輝度関数 $f_{1}(x), f_{2}(x)$ を用いた微分推定の結果を各々示す。これらの結 果から, 非線形輝度関数 $f_{1}(x)$ を用いた場合が最も微分值の 変化の検出に適していることがわかる。

以上のシミュレーションでは, 未知パラメータの推定の ために多項式展開は用いずに, $N=0$ として, 未知パラメー 夕は定数であるという設定で推定を行っている。しかし, もともとのデータが時変パラメータであることから, パラ メータの推定值も定值ではなく, 変動し, 十分に時変パラ メータの変化を追跡できており, $N=0$ でも十分に微分值の 推定に適用可能であることが，シミュレーションからわか った。 なお，実際に付加されたノイズの統計量は計算から， ピクセル $(150,400)$ と $(70,400)$ の各々で, 標準偏差が 0.2290, 0.2016 であった。

\section{4. あとがき}

本論文では, 適応パラメータ更新則を用いて, 観測デー 夕の非線形関数の微分值を推定する機構を提案した。さら に, この微分器を固定カメラの動画データの各ピクセルに 適用することにより, 指定したピクセルにおける移動体の 通過検出を行う方法をフレーム微分法や M 推定を用いた背 景画像推定を用いた方法と比較した。特に, 下に凸である 単調増加な 4 つの非線形輝度関数 $f_{1}(x), f_{2}(x), f_{3}(x), f_{4}(x)$ に より輝度の重み付けを行い, その微分值を推定することを 試みた。このような非線形輝度関数は, 低輝度域に加えて 中輝度域の重みを線形輝度よりも小さくする効果がある。 さらに, その微分值を積分演算により推定することから, ノイズの影響を減じることができることが確認できた。た だし, 非線形輝度関数 $f_{2}(x), f_{3}(x), f_{4}(x)$ の微分推定では, 中 輝度以下の変動検出が鈍くなるために, 低輝度の移動体通 過検出には向かないといった問題点がみられた。画像にお 


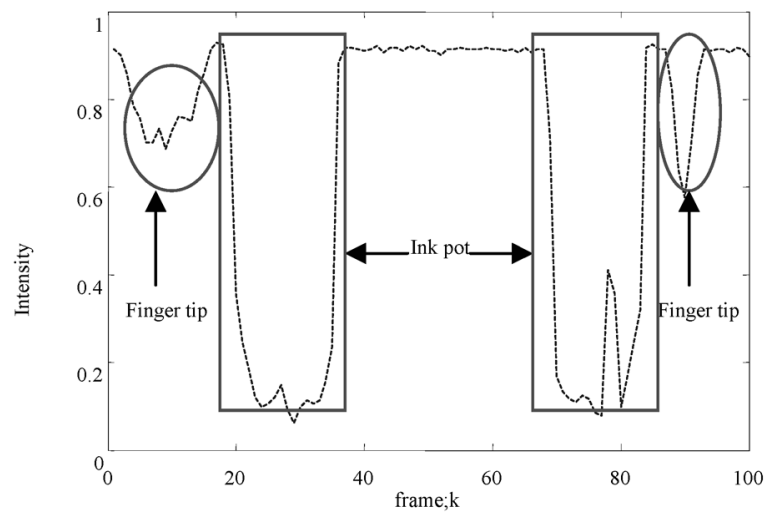

（a）ノイズのない場合

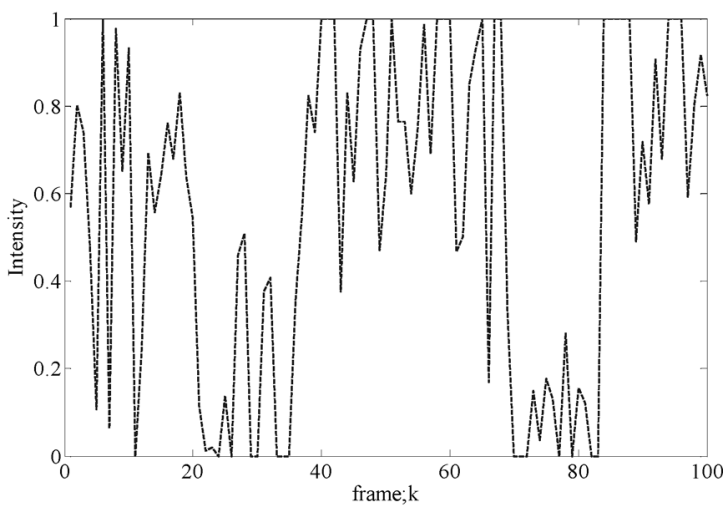

（b）ノイズのある場合

図 5 輝度時系列

Fig. 5. The intensity sequence.

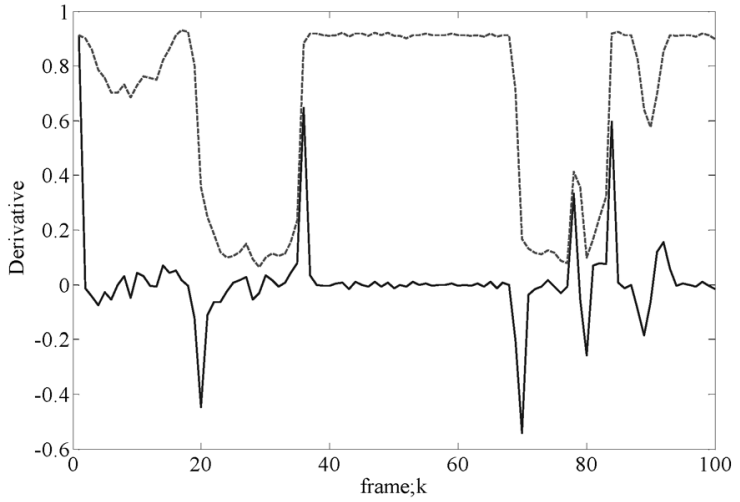

(a)ノイズのない場合

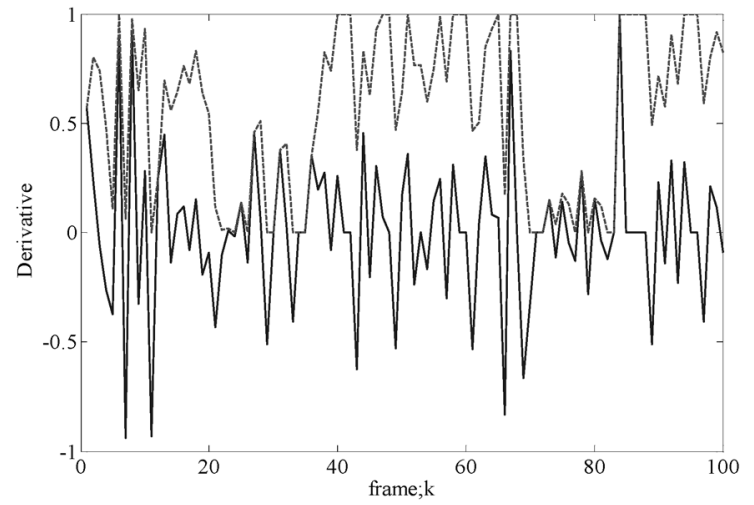

(b)ノイズのある場合

図 6 輝度時系列のフレーム微分による微分推定輝度の時系列データ (破線), 微分の推定值（実線）

Fig. 6. The intensity and estimate of differentiation.

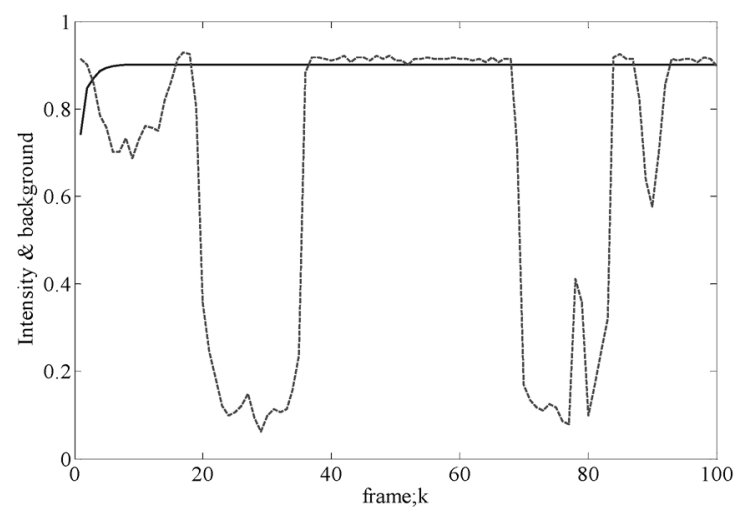

(a)ノイズのない場合

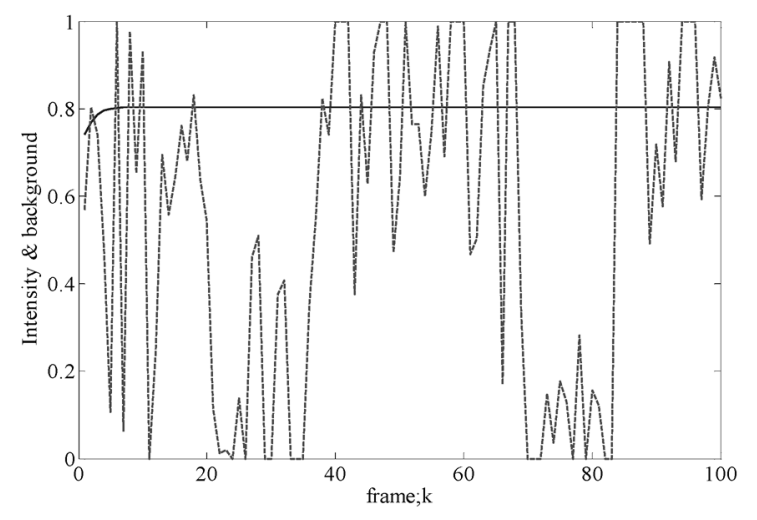

(b)ノイズのある場合

図 $7 \mathrm{M}$ 推定による背景画像推定輝度の時系列データ（破線），背景画像の推定值（実線）

Fig. 7. The background estimation by M-estimator. 


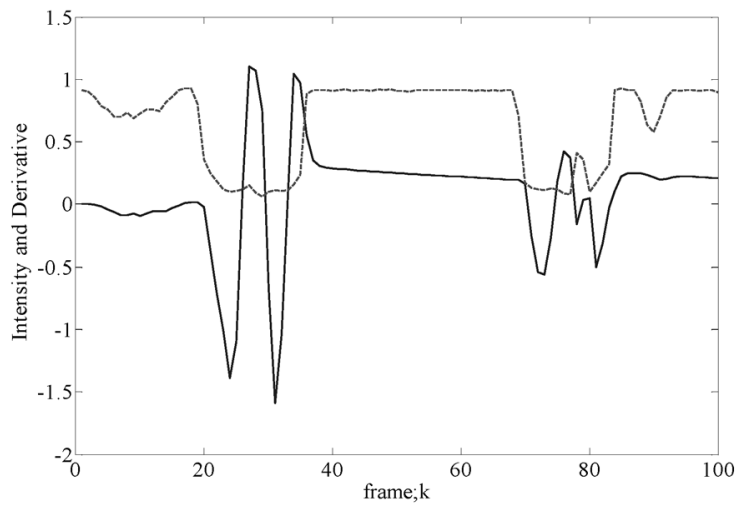

(a)ノイズのない場合

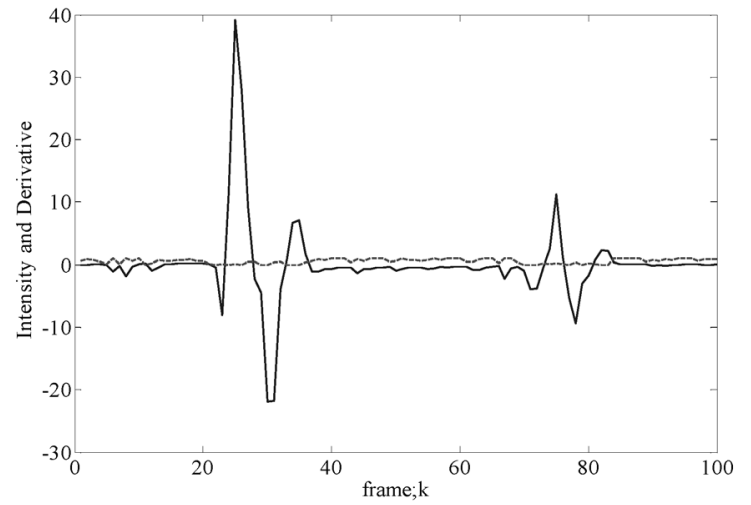

（b）ノイズのある場合

図 8 輝度時系列と非線形関数 $f_{1}(x)$ による微分推定輝度の時系列データ (破線), 微分の推定值（実線）

Fig. 8. The intensity and estimate of differentiation.

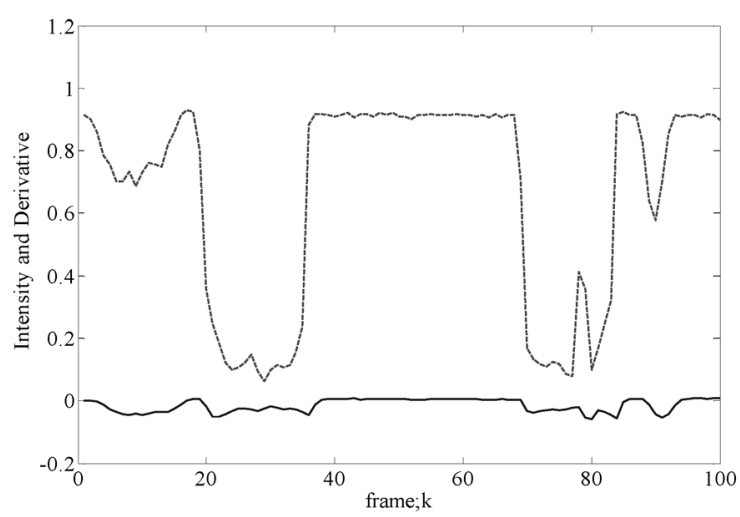

(a)ノイズのない場合

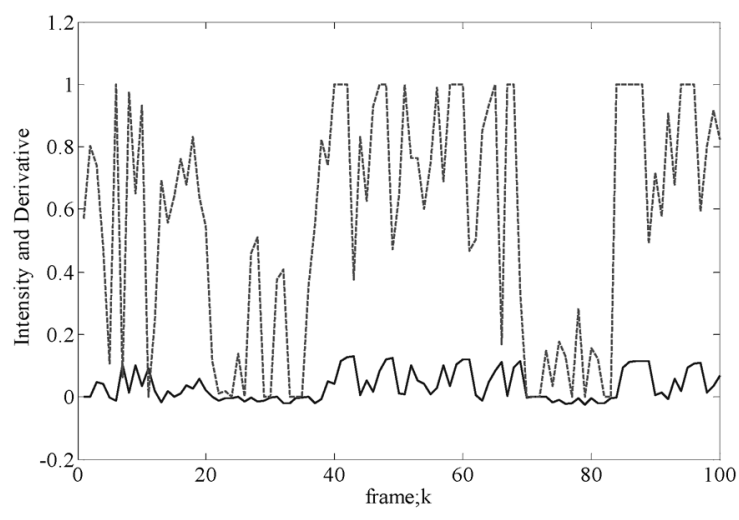

(b)ノイズのある場合

図 9 輝度時系列と非線形関数 $f_{2}(x)$ による微分推定輝度の時系列データ (破線), 微分の推定值（実線）

Fig. 9. The intensity and estimate of differentiation.

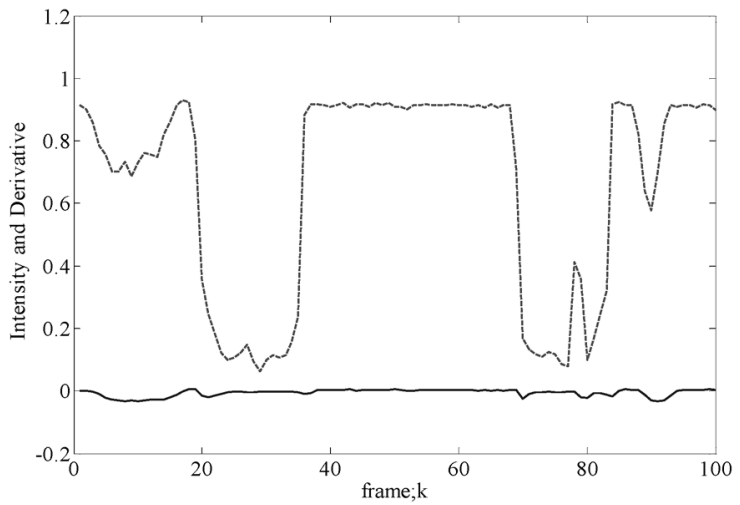

(a)ノイズのない場合

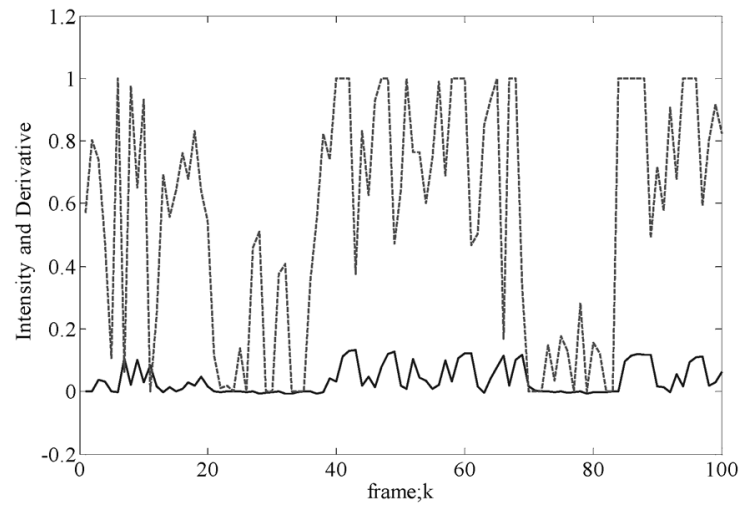

(b)ノイズのある場合

図 10 輝度時系列と非線形関数 $f_{3}(x)$ による微分推定輝度の時系列データ（破線），微分の推定值（実線）

Fig. 10. The intensity and estimate of differentiation. 


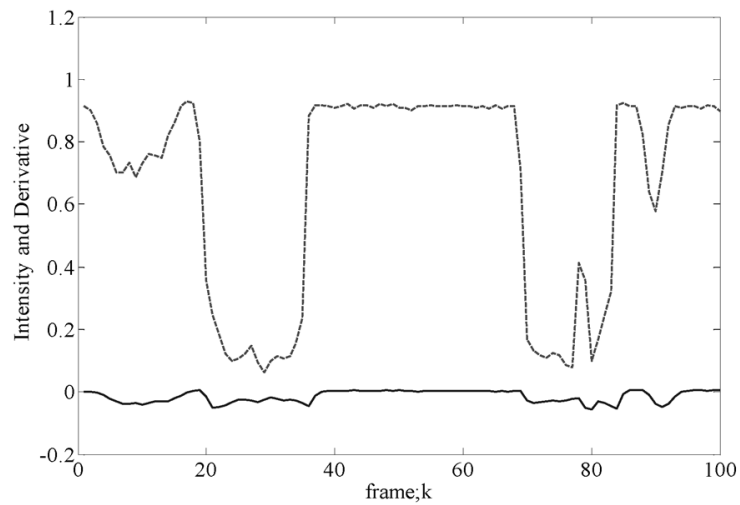

(a)ノイズのない場合

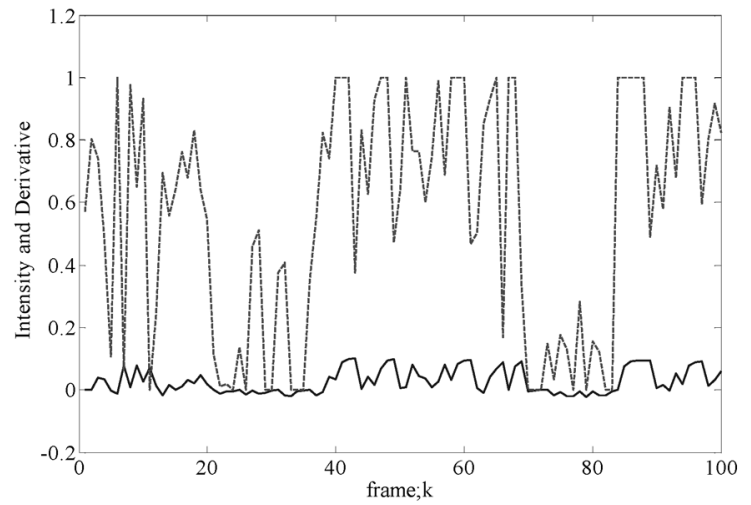

(b)ノイズのある場合

図 11 輝度時系列と非線形関数 $f_{4}(x)$ による微分推定輝度の時系列データ（破線），微分の推定值（実線）

Fig. 11. The intensity and estimate of differentiation.

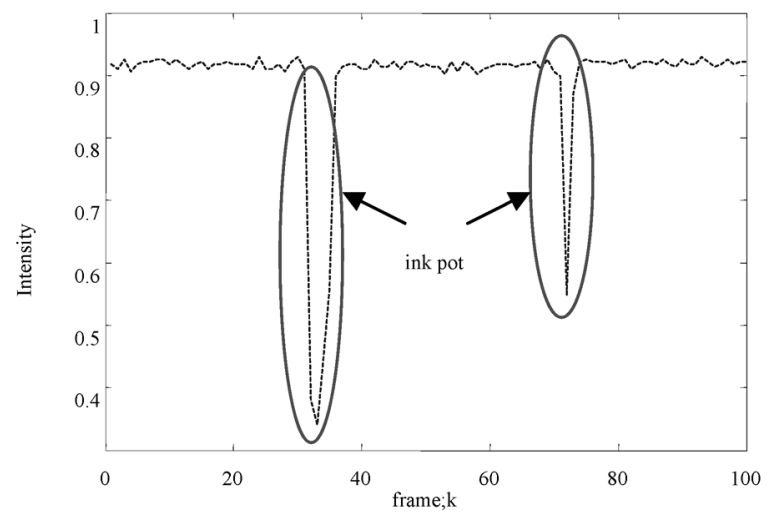

（a）ノイズのない場合

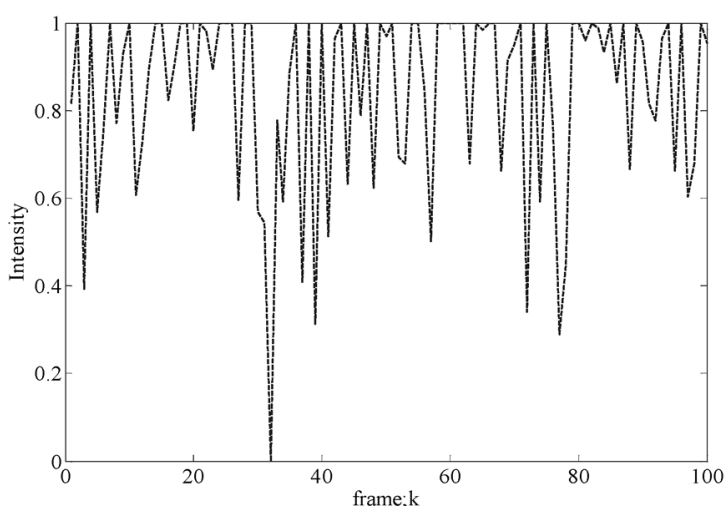

（b）ノイズのある場合

図 12 輝度時系列

Fig. 12. The intensity sequence.

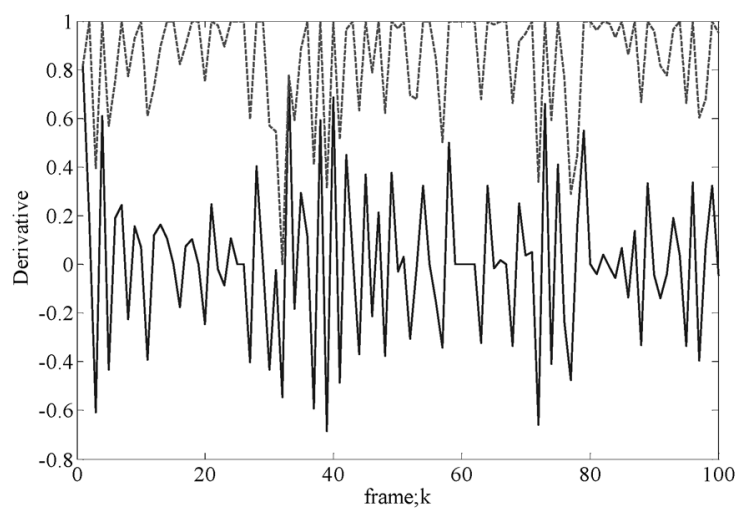

図 13 輝度時系列のフレーム微分による微分推定 輝度の時系列データ (破線), 微分の推定值 (実線)

Fig. 13. The intensity and estimate of differentiation.

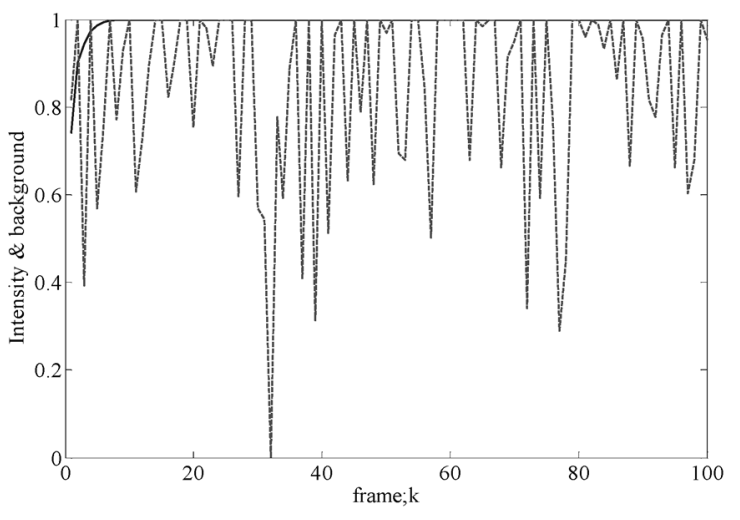

図 $14 \mathrm{M}$ 推定による背景画像推定輝度の 時系列デー夕 (破線), 背景画像の推定值（実線）

Fig. 14. The background estimation by M-estimator. 


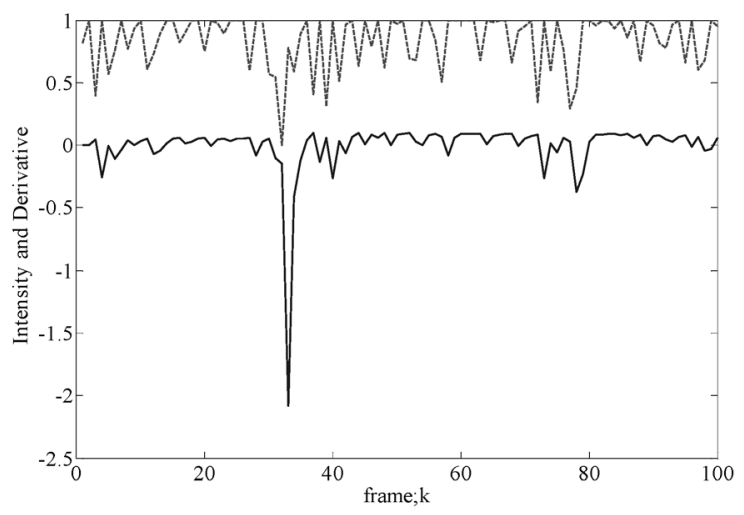

図 15 輝度時系列と非線形関数 $f_{1}(x)$ による微分推定 輝度の時系列データ (破線), 微分の推定值（実線）

Fig. 15. The intensity and estimate of differentiation.

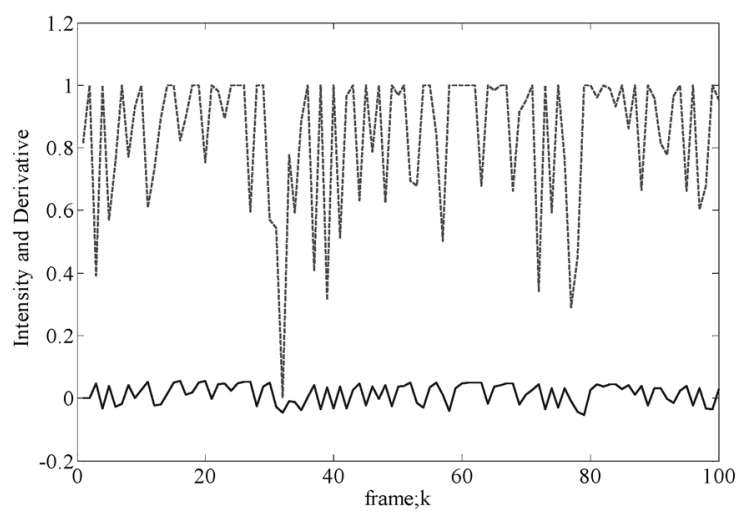

図 16 輝度時系列と非線形関数 $f_{2}(x)$ による微分推定 輝度の時系列データ (破線), 微分の推定值（実線）

Fig. 16. The intensity and estimate of differentiation.

ける種々のノイズに対して, 各々の特徵に応じた非線形輝 度関数の選定法は今後の検討課題である。また，移動体の 動き検出に本手法を適用するためには，すべてのピクセル で本手法を適用し, 移動体の認識を行う必要があるが, こ れについても今後の課題としたい。

(平成 17 年 4 月 21 日受付，平成 18 年 5 月 15 日再受付)

\section{文献}

(1) J. Richefeu and A. Manzanera : "A new hybrid differential filter for motion", ICCVG'04, Warsaw, Poland (2004) http://www.ensta.fr/ richefeu/Publications/iccvg82.pdf

(2) R. Cucchiara, C. Grana, A. Prati, and M. Piccardi: "Effective detection of moving objects, shadows and ghosts in surveillance videos",Australia-Japan Advanced Workshop on Computer Vision, Adelaide, 9-11 September (2003) http://www-staff.it.uts.edu.au/ massimo/

(3) R. Cucchiara, C. Grana, M. Piccardi, and A. Prati : "Detecting Moving Objects, Ghosts, and Shadows in Video Streams", IEEE Trans. on Pattern Analysis and Machine Intelligence, Vol.25, No.10, pp.1337-1342 (2003)

(4) S. Ibrir : "Linear time-derivative trackers", Automatica, Vol.1, No.40, pp.397-405 (2004)

(5) K. S. Narendra and A. M. Annaswamy : Stable Adaptive Systems, Prentice-Hall, Inc. (1989)

(6) P. A. Ioannou and J. Sun : Robust Adaptive Control, Prentice-Hall, Inc. (1996)

(7) H. Shimai, T. Kurita, S. Umeyama, M. Tanaka, and T. Mishima: "Adaptive Background Estimation by Robust Statistics", IEICE Trans. D, VOl.J86-D-II, No.6, pp.796-806 (2003-6) (in Japanese) 島井博行・栗田多喜夫・梅山伸二・田中 勝・三島健稳:「ロバスト 統計に基づいた適応的な背景推定法」, 信学論 D-II, J86-D-II, 6, pp.796-806 (2003-6)

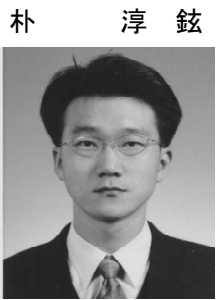

（非会員） 1972 年 4 月 15 日生。 2000 年 2 月 韓国忠川大学電気工学科卒業。2002 年大分大 学大学院工学研究科博士前期課程修了。現在大 分大学大学院工学研究科博士後期課程中。適応 制御の画像処理への応用に関する研究に従事。

松 尾 孝 美

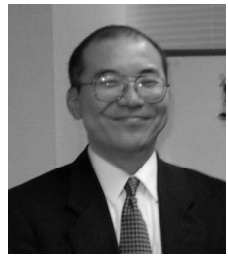

（正員） 1958 年 3 月 24 日生。 1980 年 3 月大 分大学工学部エネルギー工学科卒業。1985 年 3 月九州大学大学院総合理工学研究科博士後期 課程修了。2004 年大分大学教授, 現在に至る。 工学博士。制御理論とその応用に関寸る研究に 従事。 